\title{
BRAZILIAN AIR TRANSPORT DEMAND - A HISTORICAL VISION BASED ON FUZZY APPROACH
}

\author{
Edison Conde Perez dos Santos \\ PEP - COPPE/UFRJ, Federal University of Rio de Janeiro., Brazil \\ E-mail: edison.conde@hotmail.com \\ Edison Alves dos Santos \\ ICAO Consult, Brazil, Brazil \\ E-mail:edison.lea@hotmail.com \\ Carlos Alberto Nunes Cosenza \\ PEP - COPPE/UFRJ, Federal University of Rio de Janeiro., Brazil \\ E-mail: cosenzacoppe@gmail.com \\ Claudio Henrique dos Santos Grecco \\ PEP - COPPE/UFRJ, Federal University of Rio de Janeiro, Brazil \\ E-mail:grecco@ien.gov.br
}

Submission: 11/12/2019

Accept: 12/12/2019

\begin{abstract}
In the last fifty years, the air transport industry has undergone profound changes. Such changes could be expected to have caused changes in the demand structure of this important industry. The present study intends to analyze the possibility that this happened on the domestic segment of passengers. The work is based on a historical perspective of the evolution of the structure of this market from the fuzzy logic elaborated using fuzzy dual numbers for studies of planning of the sector, related to the period 2008 to 2015. The data used in the calibration of the model were collected from official sources of statistical information.
\end{abstract}

Keywords: fuzzy logic; fuzzy dual numbers; air transport; elasticity. 
DOI: 10.14807/ijmp.v11i6.1172

\section{INTRODUCTION}

Historically, the air transport industry has been one of the economic sectors with greater intervention of the Granting Authority, both in Brazil and in most of the countries in which this modality operates. Such intervention has been justified from two different aspects; the first one related to the guarantee of user safety and the second one justified by the need to eliminate or at least reduce possible predatory competition between the operators of those services.

As a consequence of the first aspect, following the world trend, the Brazilian authorities established a strict regulation, which defined the responsibilities of the operators with respect to the maintenance and operation of the aircraft, through the control of training, habilitation and health, physical and of those responsible for the conduct of aircraft, so-called technical crew.

The second aspect concerns service operators, subject to strict regulations that have been in place since the control of service provision, covering not only the number of frequencies offered that each could operate, but also the number of seats installed in the aircraft that would be used in the operation of these frequencies. In addition, the authorities exercised a strict control over the prices of the tickets that could be practiced by the operators in each connection, which, according to economic theory, represented an undesired control, since the Contingent Power exercised control over the two characteristic variables of the supply and demand, directly affecting the market equilibrium.

The rapid evolution of the production capacity of the new aircraft was the stimulus that the American authorities needed to defend the need for changes in the current legislation. These authorities understood that it was up to the managers of the operating companies to make decisions regarding the way their services were operated and that they should be those interested in maintaining a healthy competition in the market, a competition that would bring benefits to the user , through an offer in which a wider range of frequency alternatives and ticket prices became available.

At that time it could be observed that the operators defended a theory, called Say's Law, which said that the supply creates its own demand, thus, with these changes the services could develop new markets, producing changes in the demand structure of this modal, allowing these services were consumed by a wider range of users and ceased to be something consumed only by the elite. 
INDEPENDENT JOURNAL OF MANAGEMENT \& PRODUCTION (IJM\&P)

http://www.ijmp.jor.br

v. 11, n. 6, September - October 2020

ISSN: 2236-269X

DOI: 10.14807/ijmp.v11i6.1172

In the late 1970's, more precisely in 1978, the President of the United States enacted the "Deregulation Act," which ended the economic control of the domestic service business in the United States, while retaining all other types that were oriented to ensure the safety of operations and other technical aspects involved in the activity.

It was current thinking that, considering the demand structure of these services at that time, the income elasticity of demand in the domestic segment was around 2, that is, the activity level of the sector would grow at a rate corresponding to twice the growth rate of GDP and price elasticity was very low, possibly close to zero, thus a dynamic growth of the sector could be expected for Brazil, which made it more important to devote special attention to the planning of the sector's infrastructure, in view of the situation at national airports, than to a possible change in the regulatory framework. These changes, in the regulatory framework, could be made opportunely after the sector has consolidated.

From the presented, the work uses fuzzy dual numbers to perform a historical analysis of the behavior of the demand and indicators of user behavior, in order to offer knowledge of the behavioral indicators, as an important tool to support the decision making process of the Power Granting authority for the evaluation of possible repercussions, on the market equilibrium, resulting from the implementation of sectoral policies, and of the entrepreneurs of the sector.

Thus, in view of the natural limitations involved in the production of an article, it is possible to accept as convenient an analysis of what happened over time in the service industry of this model, based on the parameters available in technical studies elaborated by established institutions, and here is the suggestion for the elaboration of a study through which more detailed research on consumer behavior could be made, focusing mainly on aspects related to the sensitivity of the demand in relation to variations in income and prices.

\section{THEORETICAL FOUNDATION}

Definition of Dual Numbers for Mora-Camino and Cosenza (2018) The set of dual numbers “Õ” is the set of $\mathfrak{R}^{2}$ with specific addition and multiplication laws given by:

$$
\begin{aligned}
& \left(\mathrm{x}_{1}, \mathrm{y}_{1}\right)+\left(\mathrm{x}_{2}+\mathrm{y}_{2}\right)=\left(\mathrm{x}_{1}+\mathrm{x}_{2}, \mathrm{y}_{1}+\mathrm{y}_{2}\right) \\
& \left(\mathrm{x}_{1}, \mathrm{y}_{1}\right) \cdot\left(\mathrm{x}_{2}, \mathrm{y}_{2}\right)=\left(\mathrm{x}_{1} \cdot \mathrm{x}_{2}, \mathrm{x}_{1} \cdot \mathrm{y}_{2}+\mathrm{x}_{2} \cdot \mathrm{y}_{1}\right)
\end{aligned}
$$

The set "Õ" has a structure of an unity commutative ring with respect to these two laws. Its unitary element is $(1,0)$. The dual number $(0,1)$ is nilpotent of order two with respect to 
DOI: 10.14807/ijmp.v11i6.1172

multiplication. Since "Õ” presents divisors of $(0,0)$, the zero of the multiplication, it is not an integral ring, in verbis Mora-Camino and Cosenza (2018).

The subset of “ $\tilde{O}$ ” $\{(\mathrm{x}, 0) \mid \mathrm{x} \in \mathfrak{R}\}$ is a sub-ring of “Õ” and is isomorph to $\mathfrak{R}$.

Adopted notation for a dual number (x , y) of “Õ”:

$$
(x, y)=x+\varepsilon \cdot y
$$

A function $\mathrm{f}$ of a dual variable $\mathrm{x}+\varepsilon . \mathrm{y}$ is such as:

$$
f(x+\varepsilon \cdot y)=f_{1}(x, y)+\varepsilon \cdot f_{2}(x, y)
$$

where, $f_{1}$ and $f_{2}$ are two functions of the real variables $x$ and $y$.

Here is introduced the set " $\tilde{U}_{n}$ " of fuzzy dual square matrices of order $n \times n$ following the same idea used to build fuzzy dual numbers and fuzzy dual vectors. Then a fuzzy dual matrix "A" will be such as:

$$
\mathrm{A}=\left[a_{i j}\right]=\left[\mathrm{r}\left(a_{i j}\right)+\varepsilon \mathrm{d}\left(a_{i j}\right)\right]=\mathrm{r}(\mathrm{A})+\varepsilon \cdot \mathrm{d}(\mathrm{A})
$$

Where $r(A)$ is a $\mathfrak{R}^{n}$ matrix and $d(A)$ is a positive $\mathfrak{R}^{\text {nxn }}$ matrix. Then basic operations over dual square matrices will be such that:

$$
\mathrm{A}+\mathrm{B}=\mathrm{R}(\mathrm{A})+\mathrm{R}(\mathrm{B})+\varepsilon(\mathrm{D}(\mathrm{A})+\mathrm{D}(\mathrm{B})), \forall \mathrm{A}, \mathrm{B} \in \tilde{\mathrm{U}}
$$

$$
\mathrm{A} \cdot \mathrm{B}=\mathrm{R}(\mathrm{A}) \cdot \mathrm{R}(\mathrm{B})+\varepsilon(|\mathrm{R}(\mathrm{A})| \cdot \mathrm{D}(\mathrm{B})+\mathrm{D}(\mathrm{A}) \cdot|\mathrm{R}(\mathrm{B})|), \forall \mathrm{A}, \mathrm{B} \in \tilde{\mathrm{U}}
$$

Considering a complete set of " $\mathrm{n}$ " discrete events, we introduce here the notion of fuzzy dual probability distribution by considering that to each event $e_{i}, i=1$ to $n$, is assigned a dual number $\mathrm{P}\left(\mathrm{e}_{\mathrm{i}}\right)=\mathrm{p}_{\mathrm{i}}+\varepsilon \mathrm{P}_{\mathrm{i}}$. These dual numbers are supposed to satisfy the conditions, in verbis Mora-Camino F. et al., 2018.:

$$
p_{i} \in[0,1] \text { and } 0 \leq \mathrm{P}_{i} \leq \min \left\{\mathrm{p}_{\mathrm{i}}, 1-\mathrm{p}_{\mathrm{i}}\right\} \text { with } \sum_{\mathrm{i}=1}^{\mathrm{n}} \mathrm{pi}=1
$$

By analogy with the classical approach (KHINCHIN, 1957), the fuzzy dual quantity of information brought by the occurrence of event $e_{i}$ is given by:

$$
-\log \left(\mathrm{p}_{\mathrm{i}}+\varepsilon \mathrm{P}_{\mathrm{i} .}\right)=-\log \left(\mathrm{p}_{\mathrm{i}}\right)+\varepsilon \cdot \mathrm{P}_{\mathrm{i}} / \mathrm{p}_{\mathrm{i}}
$$

The fuzzy dual entropy “ $\breve{S}$ “ associated with the fuzzy dual probability distribution $\left\{p_{i}\right.$ $\left.+\varepsilon \mathrm{P}_{\mathrm{i}}, \mathrm{i}=1, \ldots, \mathrm{n}\right\}$ is given by:

$$
H=\sum_{i=1}^{n}(p i+\varepsilon \cdot P i) \cdot \log (p i+\varepsilon \cdot P i)
$$


DOI: 10.14807/ijmp.v11i6.1172

It is now possible to introduce fuzzy dual formulations of uncertain mathematical programming problems. Here we will consider only the case of linear programming, but the formalism can be applied to other classes of objective functions and restrictions. Let then consider problem $\mathrm{D}_{0}$ which is a fuzzy dual linear programming problem with fuzzy dual constraints and real decision variables, in verbis Mora-Camino and Cosenza (2018):

$$
x \in \min +\left\|\sum_{i=1}^{n}(c i+\varepsilon \cdot d i) x i\right\|
$$

Under strong constraints:

$$
\begin{aligned}
& \sum_{\mathrm{i}=1}^{\mathrm{n}}(\mathrm{aki}+\varepsilon \cdot \alpha \mathrm{ki})_{\mathrm{Xi}} \geq \mathrm{bk}+\varepsilon \beta \mathrm{k} \quad, \mathrm{k} \in\{1, \ldots, \mathrm{m}\} \text { and } \\
& \mathrm{Xi} \in R^{+}, \mathrm{i} \in\{1, \ldots, \mathrm{n}\}
\end{aligned}
$$

Regarding the topic of air transport demand modeling studies, over the past 50 years, it has made significant progress. It should be noted that although the models are applied to the global demand of a segment of traffic, the formulation of the mathematical functions of demand has been developed from the concepts of demand defined in the Theory of Microeconomics, more particularly in Consumer Theory.

It must be emphasized that the modeling of the demand for air transport services differs significantly from the modeling used in other modes. This distinction is a consequence of the availability of historical traffic data. The aviation modalities, possibly due to the fact that countries are obliged to respect the concepts and definitions of the traffic variables made by ICAO and to provide ICAO with such traffic statistics, properly disaggregated by traffic segment and by type of service, of a large collection of statistics, which allows a specific treatment for the studies of each of the relevant variables, unlike the other modalities.

And still, Fuzzy dual probabilities. Considering a complete set of $\mathrm{n}$ discrete events, we introduce here the notion of fuzzy dual probability distribution by considering that to each event $\mathrm{e}_{\mathrm{i}}, \mathrm{i}=1$ to $\mathrm{n}$, is assigned a dual number $\mathrm{P}\left(\mathrm{e}_{\mathrm{i}}\right)=\mathrm{p}_{\mathrm{i}}+\varepsilon \mathrm{P}_{\mathrm{i}}$. These dual numbers are supposed to satisfy the conditions (MORA-CAMINO; COSENZA, 2018):

$\mathrm{p}_{\mathrm{i}} \in[0,1]$ and $0 \leq \mathrm{P}_{\mathrm{i}} \leq \min \left\{\mathrm{p}_{\mathrm{i}}, 1-\mathrm{p}_{\mathrm{i}}\right\}$ with $\sum_{i=1}^{n} p i=1$

Then $\left\{\mathrm{p}_{\mathrm{i}}+\varepsilon \mathrm{P}_{\mathrm{i}}\right.$; for $\left.\mathrm{i}=1, \ldots, \mathrm{n}\right\}$ is a fuzzy dual probability distribution while $\mathrm{p}_{\mathrm{i}}+\varepsilon \mathrm{P}_{\mathrm{i}}$ is a fuzzy dual probability value.

Let $\pi_{\mathrm{i}} \in[-1,+1]$ for $\mathrm{i}=1, \ldots, \mathrm{n}$, be such as $\sum_{i=1}^{n} \pi i \cdot P i=0$, then, $\left\{\mathrm{p}_{\mathrm{i}}+\pi_{\mathrm{i}} . \mathrm{P}_{\mathrm{i}}, \mathrm{i}=1, \ldots\right.$ $\mathrm{n}\}$ is called a perfect realization of the fuzzy dual probability distribution since: 
DOI: 10.14807/ijmp.v11i6.1172

$0 \leq \mathrm{p}_{\mathrm{i}}+\pi_{\mathrm{i}} . \mathrm{P}_{\mathrm{i}} \leq 1$ and $\sum_{i=1}^{n} p i+\pi i \cdot P i=1$

The set $R_{e}$ of all perfect realizations associated to the fuzzy dual probability distribution $\left\{\mathrm{p}_{\mathrm{i}}+\varepsilon \mathrm{P}_{\mathrm{i}} ; \mathrm{i}=1, \ldots, \mathrm{n}\right\}$ is a polyedra in the $\mathrm{R}_{\mathrm{n}}$ space of the $\pi_{\mathrm{i}}^{\prime} \mathrm{s}$ and hence is a convex set.

The fuzzy dual probability associated with the complementary of event $\mathrm{e}_{\mathrm{i}}$ is then: $\mathrm{P}\left(\mathrm{e}^{\bar{e}}\right)$ $=1-\mathrm{P}(\mathrm{ei})=\left(1-\mathrm{p}_{\mathrm{i}}\right)+\varepsilon\left(1-\mathrm{P}_{\mathrm{i}}\right)$

The fuzzy dual probability associated with the occurrence of independent events ei and ej is then:

$$
\mathrm{P}\left(\mathrm{e}_{\mathrm{i}} \wedge \mathrm{e}_{\mathrm{j}}\right)=\mathrm{P}\left(\mathrm{e}_{\mathrm{i}}\right) * \mathrm{P}\left(\mathrm{e}_{\mathrm{j}}\right)=\mathrm{p}_{\mathrm{i}} * \mathrm{p}_{\mathrm{j}}+\varepsilon \mathrm{P}_{\mathrm{i}} * \mathrm{P}_{\mathrm{j}}
$$

Considering that the objective of this study is to analyze possible changes in the global demand structure of domestic air transport services, it is clear the interest in knowledge and employment, only, of the models included in the second case, that is, in the models of analysis.

The formulation of the models, both with respect to projection models and analysis models, should be preceded by a careful evaluation of the attributes that can, or should, be considered in the modeling, since the inclusion of a variable in a function depends on different aspects, among which we can highlight: the availability of consistent and coherent information, the credibility of the source, or sources, of information available, the way in which this information is presented and, mainly, the fact that generates this information (MANHEIM, 1979)

In the case of the global demand of a region or a country, it is the result of the division of the total collected by all the companies that operate in this segment of services with the transport of all the passengers by the total of Passengers. In this case the variable considered to represent the total can be the total of Passengers.Kilometers Transported Payments or the total of Passengers.Kilometers Transported. This variable is known internationally by the English name, "Yield".

Studies made by ICAO enable the formulation of a model for the calculation of passenger demand $\left(\mathrm{D}^{\mathrm{ax}}\right)$. In this work, the model was constructed in view of a dual fuzzy approach described with the following formulation (CARMONA-BENÍTEZA et al., 2017):

$$
\begin{aligned}
& \mathrm{D}^{\mathrm{ax}}{ }_{\mathrm{i}}=f\left(\mathrm{POP}_{\mathrm{i}}, \mathrm{G}_{\mathrm{DPi}}, \mathrm{Y}_{\mathrm{i}}, \mathrm{u}\right) \\
& \operatorname{Ln}\left(\mathrm{P}^{\mathrm{ktd}}{ }_{\mathrm{i}}\right)=\alpha_{0}+\alpha_{1} \cdot \operatorname{Ln}\left(\mathrm{POP}_{\mathrm{i}}\right)+\alpha_{2} \cdot \operatorname{Ln}\left(\mathrm{G}_{\mathrm{DP}}\right)+\alpha_{3} \cdot \operatorname{Ln}\left(\mathrm{Y}_{\mathrm{i}}\right)+\mathrm{u}
\end{aligned}
$$

Where, 
$\mathrm{P}_{\mathrm{k}}^{\mathrm{ktd}}=$ total number of passengers transported in the region over a period of time, usually one year;

$\mathrm{POP}_{\mathrm{i}}=$ Population of Region $\mathrm{i}$;

$\mathrm{GDPi}_{\mathrm{D}}=$ Gross domestic product of region i;

$\mathrm{Y}_{\mathrm{i}}=$ Yield of the industry operating in region $\mathrm{i} ; \mathrm{u}=$ Term representative of the error;

\subsection{The Model of the Institut Du Transport Aerien (ITA) - Brazil Agency}

The changes in the air transport industry in Brazil stimulated non- governmental institutions to be interested in the study of the behavior of the demand of these services. Following the study prepared by the ITA headquarters in France, the "Institut $\mathrm{Du}$ Transport Aerien" (ITA) - Brazil Agency published a study in 1996 (SANTOS, 1996), which sought to outline the evolution of the transportation service activity air traffic in Brazil, in general, and the probable prospects of this economic segment, in particular, for a 20-year horizon. In this work the calibrated model had the following expression with fuzzy dual numbers (PROFILLIDIS, 2000):

$$
\widetilde{P}_{\text {ktd }}=-7+0,9 \cdot \widetilde{G}_{\mathrm{PDi}}-0,6 \cdot \widetilde{Y}_{\mathrm{d}}+\widetilde{D}
$$

Where,

$\widetilde{D}=$ Dummy variable representative of the influence of the entry into force of the Real Plan.

\section{ESTIMATION OF CURRENT DEMAND FUNCTION}

The lack of a study that contained a model, analogous to those presented in the previous item, where the data on the changes in the air transport industry in the recent past were included in its calibration, suggested the need to update the demand function used in the studies presented in the above items so that some kind of inference could be made about the possible influence of the measures adopted by the Brazilian authorities.

In this sense, for the first time in history, the financial sector attended the fair of Le Bourget in France in 2013 and, at that fair, financial companies were present considering the possibility of doing business with companies in the sector, air transport industry, for the first time in its history, was considered as an activity capable of attracting financial investors. This is particularly interesting for all operators of these services, but for Brazilian companies in 
DOI: 10.14807/ijmp.v11i6.1172

particular this is of particular importance given the capital constraints of these companies (PAVAUX, 1984).

Thus, considering that:

- The objective of the present study is to analyze the possible influence of the recently observed changes in the Brazilian economy on the structure of the demand for air transport services in the domestic passenger segment;

- there is a set of previous studies on the behavior of the global demand for services that allow us to envisage how this structure behaved in the recent past;

- In these studies, the parameters related to the determinant variables of demand formation, relevant to the proposed analysis, are present in the available demand functions; and

- no recent studies were found that contained some demand model with similar formulation to those analyzed here, not even some other model that could be comparable.

In this way, the work of data collection used as sources for this activity the official bodies for collecting and disseminating statistical and economic information. The economic and financial information of air transport was obtained from the Transport Yearbook, single volume, 2015, published by the National Civil Aviation Agency - ANAC and, for socioeconomic information, the source used was the Getúlio Vargas Foundation - FGV.

Considering that the revenue information collected was expressed in current values of "Reais (R\$)", the General Price Index - IGP-DI, published by IBRE/FGV, and the IGP-DI was used for the month of December, corresponding to the one accumulated in the period from January to December of each year.

The table below shows the variables related to the variables Gross Domestic Product of Brazil, Domestic Passenger Traffic, Domestic Passenger Traffic Revenue, in current values, Domestic Passenger Traffic Revenue, in constant values related to 2008 and Domestic Traffic Yield of Passengers, in constant values, 2008.

The total passenger revenue was calculated on the total revenue from the domestic segment in year " $\mathrm{i}$ ", presented in the Yearbook, the percentage representing the sum of the percentages related to the share of ticket revenues in each year plus the percentage of excess baggage revenues that same year. 
ISSN: 2236-269X

DOI: 10.14807/ijmp.v11i6.1172

$$
\begin{aligned}
& R_{i} P_{i}=R_{i}^{\top}{ }^{*}\left(P_{i}^{C}+P_{i}^{G}\right) \\
& \widetilde{H}\left(R^{P_{i}}\right)=\left(\left(R_{i}^{P_{i}}-R_{i-1}^{P_{i}}\right) /\left(R_{i}^{P_{i}}\right)\right)
\end{aligned}
$$

Where:

$\mathrm{R}_{\mathrm{i}}=$ Total revenue of domestic segment passes, in year $\mathrm{i}$;

$\widetilde{H}\left(\mathrm{R}_{\mathrm{i}}\right)=$ Entropy of Total revenue of domestic segment passes, in year $\mathrm{i}$;

$\mathbf{R}_{\mathrm{i}}^{\mathrm{T}}=$ Total revenue from the domestic passenger segment, in year i;

$\mathrm{PC}_{\mathrm{i}}=$ Percentage share of ticket revenue in year $\mathrm{i}$ over total revenue from the domestic segment; and

$P^{G}=$ Percentage share of excess passenger baggage revenue in year i over total domestic segment revenue.

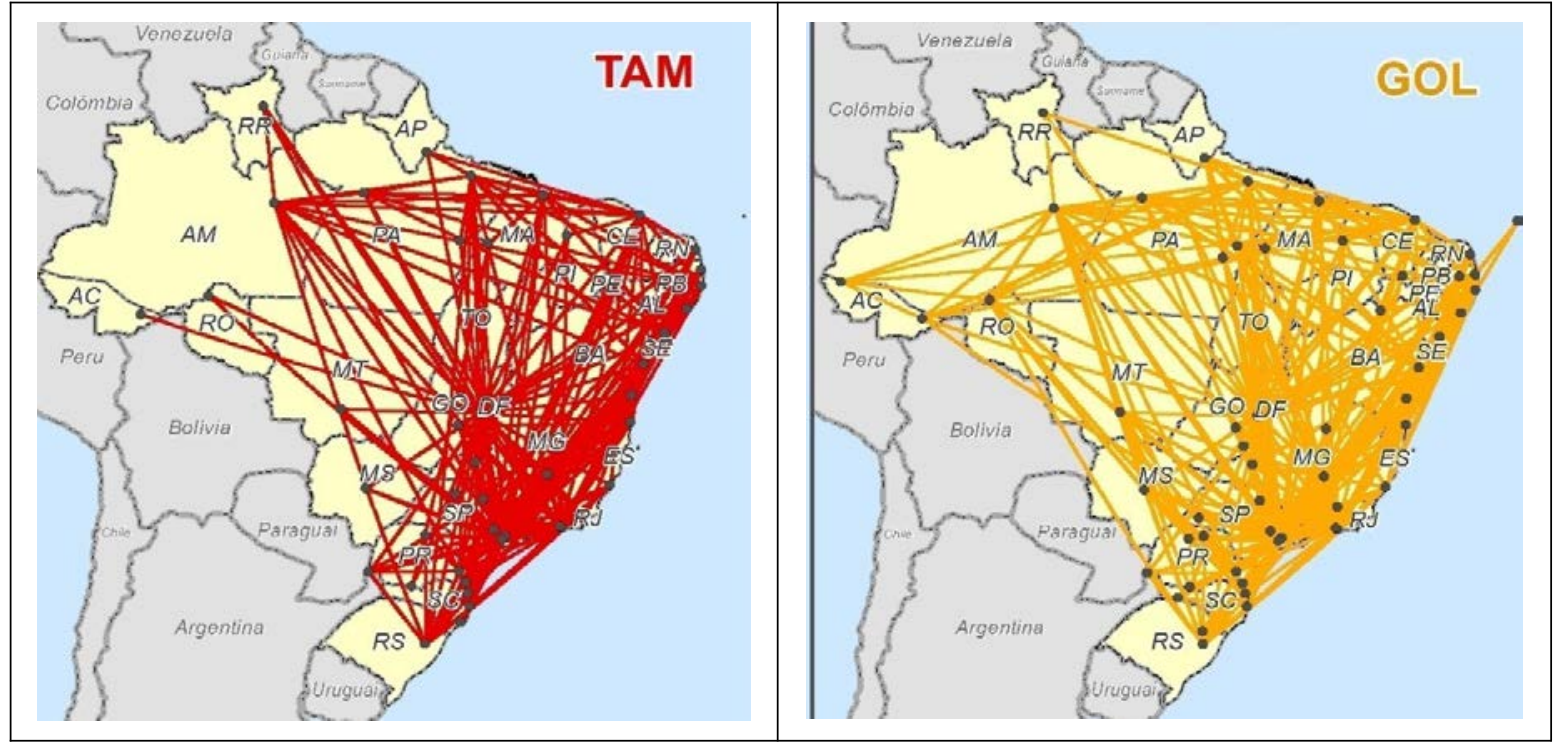

Figure 1: Evolution of Domestic Demand Source: ANAC (2015). 


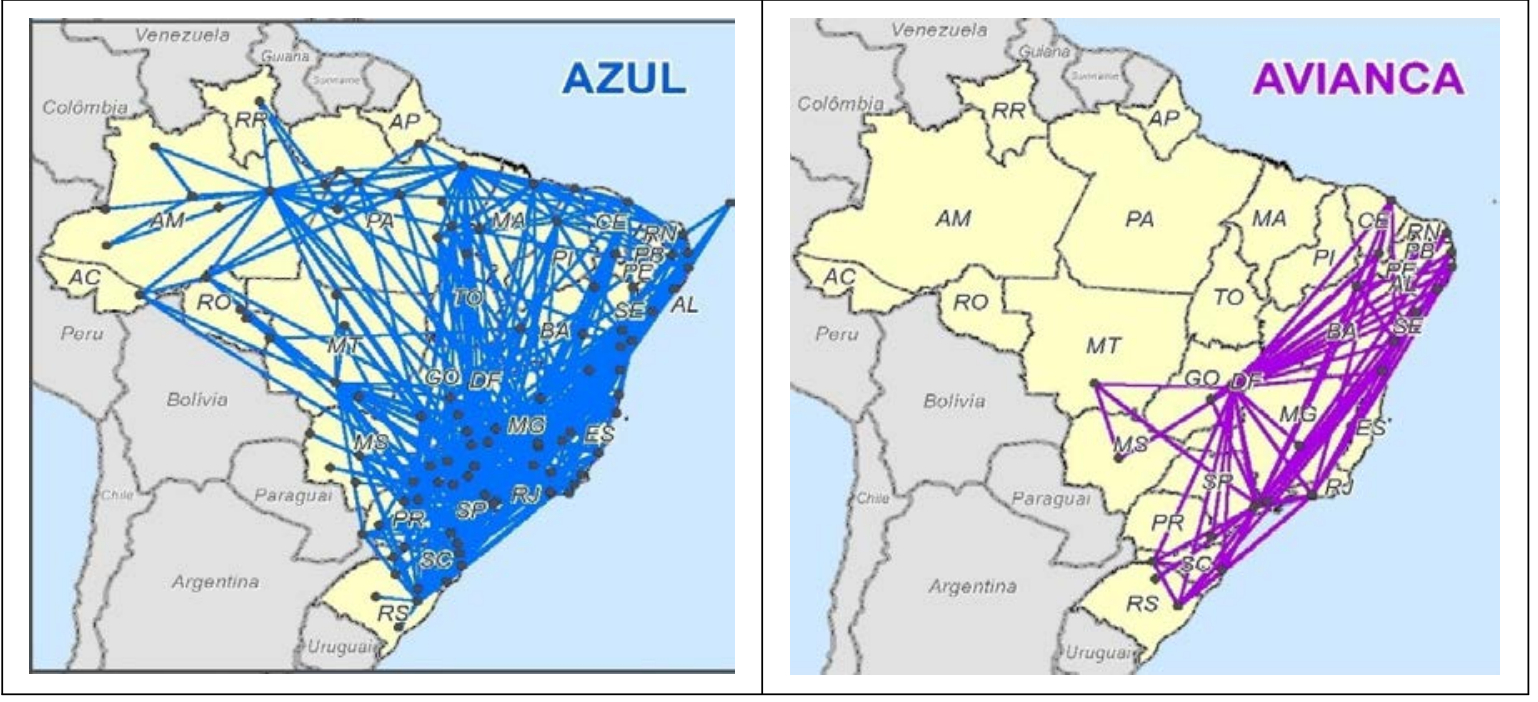

Figure 2: Evolution of Domestic Demand Source: ANAC (2015)

Table 1: Evolution of Total revenue of domestic segment passes, in year $\mathrm{i}$

\begin{tabular}{|c|c|c|c|}
\hline YEAR & $\begin{array}{c}\text { COST (R\$) } \\
\text { per 2008 }(\varepsilon)\end{array}$ & $\begin{array}{c}\mathbf{R}^{\boldsymbol{P}_{i}} \\
\text { (Millions) }\end{array}$ & $\check{\mathbf{H}}^{\left(\mathbf{R}^{{ }_{i}}\right.} \mathbf{~}$ \\
\hline 2008 & 0,29 & 14.204 & - \\
\hline 2009 & 0,26 & 14.727 & 0.04 \\
\hline 2010 & 0,24 & 18.314 & 0.20 \\
\hline 2011 & 0,23 & 21.260 & 0.14 \\
\hline 2012 & 0,22 & 23.389 & 0.09 \\
\hline 2013 & 0,23 & 26.957 & 0.13 \\
\hline 2014 & 0,23 & 29.190 & 0.08 \\
\hline 2015 & 0,22 & 31.268 & 0.07 \\
\hline
\end{tabular}

The synthesis of the evolution of the parameters related to attributes considered as determinants of demand formation, together with documents published by agencies and institutions dedicated to the study of this demand, complemented by the one obtained in the process of adjustment with current data, is presented in the following table:

Table 2: Evolution of Domestic Demand (ANAC, 2008 - 2015) 
DOI: 10.14807/ijmp.v11i6.1172

\begin{tabular}{|c|c|c|c|}
\hline YEAR & $\begin{array}{c}\text { COST (R\$) } \\
\text { per 2008 ( } \boldsymbol{\varepsilon} \text { ) }\end{array}$ & $\begin{array}{c}\mathbf{G P D}_{\mathbf{d}} \\
\text { (Millions) }\end{array}$ & $\begin{array}{c}\text { P }_{\text {KTd }} \\
\text { (10xThousands) }\end{array}$ \\
\hline 2008 & 0,29 & 3.186 & 49.714 \\
\hline 2009 & 0,26 & 3.175 & 56.862 \\
\hline 2010 & 0,24 & 3.415 & 70.279 \\
\hline 2011 & 0,23 & 3.508 & 81.462 \\
\hline 2012 & 0,22 & 3.574 & 87.047 \\
\hline 2013 & 0,23 & 3.682 & 88.244 \\
\hline 2014 & 0,23 & 3.685 & 93.333 \\
\hline 2015 & 0,22 & 3.545 & 94.372 \\
\hline
\end{tabular}

\section{CONCLUSION}

From the information presented in Table 2, it can be observed that the structure of the demand for air transport services, in the domestic passenger segment, has been following the trend of the national economy.

Income elasticity presented a change of almost $100 \%$, going from 0.77 to 1.34 , in the period between 1974 and 1982, when the models were adjusted. This change was probably influenced by Brazil's significant GDP growth, which in the 1970's evolved at an average geometric growth rate of $9.57 \%$ per year, according to the GDP data published by FGV. Regarding the price variable, there are no concrete data on its evolution in this period, which restricts any assertion regarding possible yield variations, however, during this period, no information was obtained on stimulating companies in the sense of price reduction.

Through the estimator of the price elasticity of demand, captured in the result of the work of adjusting the mathematical function of demand with the recent data, it can be admitted that the measures adopted by the Brazilian authorities had a positive result.

These results allow admitting that the freedom introduced in the management of the economic aspects of the activity affected the market positively, however this is a punctual conclusion and, although important, should be the object of a more in depth study to evaluate the stability, in time of these measures.

Thus, considering that:

- the Brazilian economy has undergone profound changes;

- there are effects that may be of short duration, as was observed in relation to the income elasticity at the time of implementation of the Cruzado’s Plan; 
- a set of laws that are expected to have a direct impact on national development are in progress at the National Congress;

- during the more than 40-year period involved in the models included in the work, there were profound changes in the provision of these services, including the creation and subsequent termination of regular third-level air transport services;

- the analysis presented here was based only on numerical information of the parameters raised in previous studies;

- knowledge of the market structure, including mainly demand, is of the utmost importance to support the decision-making process of the authorities responsible for managing the sector and the entrepreneurs who, with this knowledge, can evaluate possible consequences of the decisions taken, it is suggested that:

While the results presented here are relevant to a first approximation of the problem, it is important that a more in-depth study on the national air transport services market is undertaken, both domestically and internationally, through which one can thoroughly analyze the consequences and their stability, in time, arising from:

- extinction of the Integrated Regional Air Transport System (SITAR) on the level of services provided to users;

- lack of access of third-level service operators to possible financing facilities for new aircraft;

- difficulty of access of the smaller operators to aircraft adapted to the type of service rendered;

- influence of the variations on the determinants variables of the demand formation on the service demand structure;

- assessment of the stability over time of the consequences of the measures taken.

\section{REFERENCES}

CARMONA-BENíTEZA, R. B.; NIETO, N. R.; MIRANDA, D. (2017) An

Econometric Dynamic Model to estimate passenger demand for air transport industry,

Transportation Research Procedia, v. 25, p. 17-29;

PDSAC (1975) Civil Aviation System Development Plan. Rio de Janeiro;

INTERSTATE AVIATION COMMITTEE (IAC). (2006) Detailed Demand Study of Brazilian Airports. Rio de Janeiro; 
KHINCHIN A. I. (1957) Mathematical foundations of information theory, Dover Books on Mathmatics.

KRUGMAN, P.; WELLS, R. (2009) Microeconomics - second edition - Worth Publishers; MANHEIM, M. L. (1979) Fundamentals on Transportation System Analysis-Vol 1 - Basic Concepts, The MIT Press;

MORA-CAMINO, F.; COSENZA, C. A. N. (2018) Fuzzy Dual Numbers - Theory and Applications, Studies in Fuzziness and Soft Computing, Volume 359, Springer.

NATIONAL CIVIL AVIATION AGENCY - ANAC (2008-2015) Brazilian air transport directory. in Feb, 2019 https://www.anac.gov.br/dadosabertos.

SANTOS, E. A.; NEVES, C.; MEDEIROS, E. J. L. (1996) Air Transport in Brazil: Horizon 2020, Institut Du Transport Aerien - Agência Brasil - Rio de Janeiro;

PAVAUX, J. (1984) L'economie Du Transport Aerien - La Concurrence impraticable - Economica - set 1984;

PROFILLIDIS, V. A. (2000) Econometric and fuzzy models for the forecast of demand in the airport of Rhodes, Journal of Air Transport Management, v. 6, p. 95-100. 